\title{
Adrenal Hemangioma: A Common Tumor at Uncommon Site
}

\author{
Ritu Asnani ${ }^{1}$ Kishan Prasad Hosapatna Laxminarayana ${ }^{1}$ \\ Sajitha Kaliyat ${ }^{1}$ Kalale R. Bhagvan² \\ Praveen Kumar R. Bhat ${ }^{2}$ Shreya Goel' \\ ${ }^{1}$ Department of Pathology, K.S. Hegde Medical Academy, Nitte \\ (deemed to be) University, Mangalore, Karnataka, India \\ ${ }^{2}$ Department of General Surgery, K.S. Hegde Medical Academy, \\ Nitte (deemed to be) University, Mangalore, Karnataka, India

\begin{abstract}
Address for correspondence Kishan Prasad Hosapatna Laxminarayana, MD, Department of Pathology, K.S. Hegde Medical Academy, Nitte (deemed to be) University, Mangalore 575018, Karnataka, India (e-mail: kishanprasadhl@nitte.edu.in).
\end{abstract}

J Health Allied Sci ${ }^{\mathrm{NU}}$ 2022;12:87-89.

\begin{abstract}
Keywords

- cavernous hemangiomas

- benign tumors

- dilated vascular channels

Adrenal hemangiomas are rare vascular tumors. These are benign, mostly nonfunctioning and asymptomatic. Cavernous adrenal hemangiomas are more common in the elderly, with female preponderance. A computed tomography (CT) scan can diagnose their benign nature. Most cases are managed surgically, and laparoscopy is the most common approach followed nowadays.

A young female presented with nausea, pain, and a vague mass palpable in the right abdomen. With CT findings favoring benign lesion or nonfunctioning adenoma but symptomatic, the patient had to undergo diagnostic laparoscopy and adrenalectomy. Adrenal hemangiomas are rare lesions. Moreover, involving a young female further makes their diagnosis difficult. Hence, they must be kept as one of the differential diagnosis in evaluation of adrenal mass in young females.
\end{abstract}

\section{Introduction}

Hemangiomas are benign vascular tumors. ${ }^{1}$ Cavernous hemangioma, a subtype, is still a rare entity in the adrenal gland and was first published by Johnson and Jeppesen in 1955 . These represent $0.01 \%$ of adrenal tumors. Literature shows 67 cases of adrenal cavernous hemangioma published between the year 1955 and 2018. ${ }^{2}$ Such masses are usually nonfunctioning and asymptomatic. This is a rare case of incidentally detected cavernous hemangioma in the adrenal gland post adrenalectomy.

\section{Case Report}

A 30-year-old female complained of nausea and dull aching pain in the right lower abdomen for 14 days. There was no history of hypertension, palpitation, sweating, weight loss, and loss of appetite. General examination showed a vague

published online Jun 04, 2021
DOI https://doi.org/

$10.1055 / \mathrm{s}-0041-1730745$ ISSN 2582-4287 mass of $3 \times 3 \mathrm{~cm}$, firm in consistency in the right lumbar region with a dull note on percussion. Contrast-enhanced computed tomography (CECT) abdomen showed enlarged right adrenal gland with well-defined heterogeneous enhancing lesion with well-preserved fat planes suggestive of the benign lesion or a nonfunctioning adenoma. Biochemical and hematological investigations were unremarkable. The patient underwent diagnostic laparoscopy with right adrenalectomy. Gross photograph ( - Fig. 1 ) shows specimen measuring $5.3 \times 5.2 \times 2.1 \mathrm{~cm}$, cystic in consistency with multiple cysts on cut surface exuding hemorrhagic fluid. Microscopy showed peripherally compressed residual adrenal tissue. The lesion showed multiple spaces filled with blood and lined by flattened endothelium ( - Figs. 2 and $\mathbf{3}$ ) along with few thrombosed vessels. Features were suggestive of right adrenal cavernous hemangioma with xanthogranulomatous changes. The postoperative period was uneventful. 


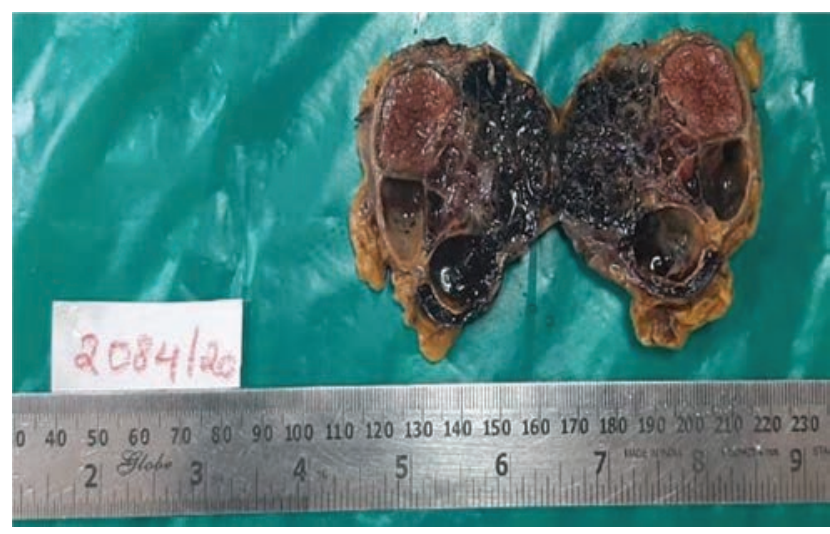

Fig. 1 Gross photograph showing multiple cysts exuding hemorrhagic fluid.

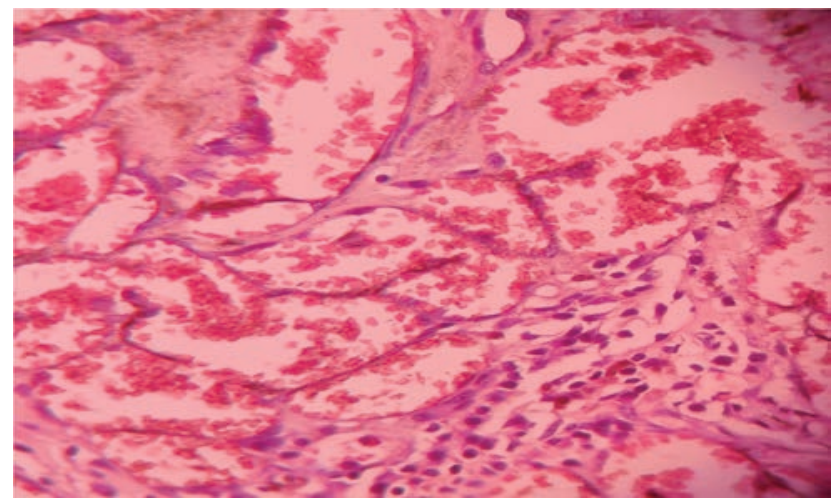

Fig. 3 Histopathology showing blood-filled spaces lined by flattened endothelium (hematoxylin and eosin stain: 40x).

\section{Discussion}

Adrenal cavernous hemangioma is commonly present in the sixth and seventh decades of life with a female to male ratio of $2: 1{ }^{3}$ There is usually no preference for laterality. The mean size noted in the literature is $11 \mathrm{~cm} .^{2}$ In most cases, the patients have been asymptomatic with normal metabolic workup. ${ }^{3,4}$ Some presented with nonspecific symptoms like vague abdominal pain, bloating, heaviness, bilateral flank pain, and chronic abdominal distension. ${ }^{2.5}$ These tumors gradually increase in size and may reach 10 to $35 \mathrm{~cm}$ in diameter $^{3}$ and cause mass effects. Literature shows other less common presenting features: night sweats and generalized fatigue, hyperfunctioning adrenal mass, subclinical Cushing syndrome, hypertension as presenting symptom with normal adrenal functions, and hyperaldosteronism with hypokalemia, hypovolemic shock due to spontaneous rupture. ${ }^{6-8}$ Our case presentation is unique, considering the patient's age, only 30 years, making this already rare lesion further rare. Also, the size was $5.3 \mathrm{~cm}$ in greatest dimension. Moreover, contrary to the majority of asymptomatic presentations, it presented with nausea and vague abdominal pain.

Hemangiomas are benign vascular tumors characterized by increased blood vessels or abnormal vessels filled with blood. These mainly involve head and neck but can seldom be more extensive and can occur internally. Malignant change

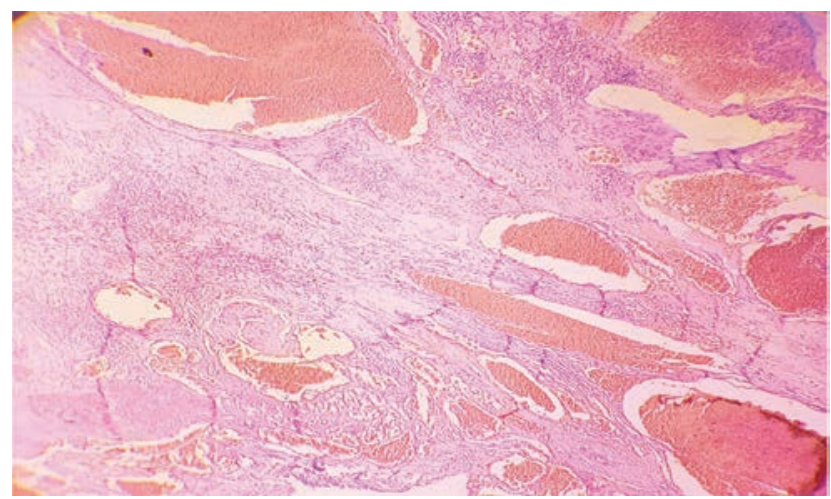

Fig. 2 Histopathology showing multiple vascular spaces filled with blood (hematoxylin and eosin stain: 40x).

is rarely seen. Based on histology and clinical variants, it has four subtypes: capillary, cavernous, juvenile and pyogenic. Cavernous hemangiomas are infiltrative, frequently involve deep structures, and do not spontaneously regress. Histology shows an unencapsulated mass with infiltrative borders made of large, cavernous blood-filled vascular spaces separated by connective tissue stroma. ${ }^{1}$

A CT scan usually diagnoses benign vascular tumors. The characteristic feature of adrenal hemangioma in CECT is a peripheral patchy enhancement and highly dense outer rim. ${ }^{4}$ Specificity of $\mathrm{CT}$ and magnetic resonance imaging is low when diagnosing adrenal malignancy, but benign masses are quickly picked up. ${ }^{9}$ Final diagnosis in most cases is by histopathology in postsurgical resection.

Most hemangiomas are managed surgically. Small asymptomatic, benign-looking masses on radiography can be managed conservatively with close follow-up. Symptomatic, large masses, or with suspected malignant potential have to undergo resection. ${ }^{2}$ Laparoscopic adrenalectomy is known to have lesser complications and better postoperative results than open adrenalectomy. ${ }^{10}$ But despite the advantages of laparoscopy, the open technique is preferred when mimicking malignancy.

\section{Conclusion}

Adrenal cavernous hemangioma is a rare lesion in itself. Moreover, presenting at the age of 30 years makes the case further unique. It is essential to consider this lesion as a differential diagnosis for adrenal masses, even in young patients, to avoid spontaneous hemorrhage or intraoperative chances of bleeding and hypovolemic shock during hemangioma excision.

\section{Conflict of interest}

None declared.

\section{References}

1 Mitchell RN. Blood vessels. In: Robbins and Cotran Pathologic Basis of Disease. 9th edition. Noida: Thieme Medical and Scientific Publishers Pvt. Ltd. 2015;483-521 
2 Degheili JA, Abou Heidar NF, El-Moussawi M, Tawil A, Nasr RW. Adrenal cavernous hemangioma: a rarely perceived pathology-case illustration and review of the literature. Case Rep Pathol 2019;2019:846389010.1155/2019/8463890

3 Feo CV, De Troia A, Pedriali M, et al. Adrenal cavernous hemangioma: a case report. BMC Surg 2018;18(1):103

4 Zemni I, Haddad S, Hlali A, Manai MH, Essoussi M. Adrenal gland hemangioma: a rare case of the incidentaloma: case report. Int J Surg Case Rep 2017;41:417-422

5 Pang $\mathrm{C}$, Wu P, Zhu G. A rare cavernous hemangioma of the adrenal gland. Urol Case Rep 2015;3(4):120-122

6 Oishi M, Ueda S, Honjo S, Koshiyama H, Yuba Y, Takabayashi A. Adrenal cavernous hemangioma with subclinical Cushing's syndrome: report of a case. Surg Today 2012;42(10):973-977
$7 \mathrm{Ng} \mathrm{AC}$, Loh HL, Shum CF, Yip SK. A case of adrenal cavernous hemangioma presenting with progressive enlargement and apparent hormonal hypersecretion. Endocr Pract 2008;14(1):104-108

8 Paluszkiewicz P, Ambroziak I, Hołyńska-Dąbrowska K, Siezieniewska-Skowrońska Z, Paluszkiewicz A. Spontaneous rupture of adrenal haemangioma mimicking abdominal aortic aneurysm rupture. Arch Med Sci 2010;6(1):122-125

9 Ishigami K, Stolpen AH, Sato Y, Dahmoush L, Winfield HN, Fajardo LL. Adrenal adenoma with organizing hematoma: diagnostic dilemma at MRI. Magn Reson Imaging 2004;22(8):1157-1159

10 Elfenbein DM, Scarborough JE, Speicher PJ, Scheri RP. Comparison of laparoscopic versus open adrenalectomy: results from American College of Surgeons-National Surgery Quality Improvement Project. J Surg Res 2013;184(1):216-220 